\title{
OCCUPATIONAL ACCIDENTS IN ARTISANAL MINING IN KATANGA, D.R.C.
}

\author{
MYRIAM ELENGE ${ }^{1,3}$, ALAIN LEVEQUE ${ }^{2,3}$, and CHRISTOPHE DE BROUWER ${ }^{1,3}$ \\ ${ }^{1}$ Free University of Brussels, Brussels, Belgium \\ Research Center Environmental and Occupational Health \\ ${ }^{2}$ Free University of Brussels, Brussels, Belgium \\ Research Center for Epidemiology, Biostatistics and Clinical Research \\ ${ }^{3}$ Free University of Brussels, Brussels, Belgium \\ School of Public Health
}

\begin{abstract}
Introduction: This study focuses on accidents in artisanal mining, to support policies improving miners' employability. Materials and Methods: Based on a questionnaire administered in November 2009 to a sample of 180 miners from the artisanal mining of LUPOTO, in the Province of Katanga, we explored significant trends between the accidents and their consequences and behavioral or sociological variables. Results: During the 12 months preceding the study, 392 accidents occurred, affecting $72.2 \%$ of miners. Tools handling represents $51.5 \%$, of the accidents' causes, followed by handling heavy loads (32.9\%). Factors such as age, seniority or apprenticeship did not generate significant differences. Contusions were the most common injuries $(50.2 \%)$, followed by wounds (44.4\%). These injuries were located in upper limbs (50.5\%) and in lower limbs (29.3\%). 80.5\% of miners were cared for by their colleagues and $50 \%$ of them could not work for more than 3 days. Physical sequelae were reported by $19 \%$ of the injured miners. Discussion: Many surveys related to accidents in the area of artisanal mining report such high frequency. The unsuitability of tools to jobs to be done is usually raised as one of the major causes of accidents. The lack of differentiation of the tasks carried out in relation to age is another factor explaining the lack of protective effect of seniority as it minimizes the contribution of experience in the worker's safety. The apprenticeship reported is inadequate; it is rather a learning by doing than anything else. That is why it lacks protective effect. Low income combined with precariousness of artisanal mining are likely to explain the low level of work stoppages. Conclusion: Tools improvement associated with adequate training seem to be the basis of accident prevention. Availability of suitable medical care should improve artisanal miners' recovery after accidents.
\end{abstract}

Key words:

Accident, Artisanal mining, Safety, Katanga

\section{INTRODUCTION}

Despite significant progress in the area of safety, in many countries mining still remains the industry where accidents occur most often [1]. Artisanal mining, which has the particularity of occurring in a casual framework, in a total ignorance of good practices and mining rules [2], is therefore an even greater source of accidents.
In the Democratic Republic of Congo, the risks emerging from such activity are especially high since it is a survival activity [3], exercised in a context of marked insecurity, in margins of regulation and good practice [4].

Workplaces analyses performed in artisanal mines of Katanga highlighted various risk factors [5], mainly toxicological hazards exacerbated by the manipulation, without adequate

Received: May 8, 2012. Accepted: September 26, 2012.

Corresponding author: M. Elenge, Research Center for Environmental and Occupational Health, Research School of Public Health, Free University of Brussels, Brussels, Belgium (e-mail: melengem@ulb.ac.be). 
protection, of gravel ore containing heavy metals and other toxic substances, musculoskeletal disorders related to poor work postures, improper handling of heavy load and accidents due to noncompliance with the mining standards.

Despite the importance of these risks, few studies have been carried out to objectivize and analyze them in order to identify useful information for improving occupational health and safety management in this type of environment. In our previous studies, we evidenced the impact of working conditions on miners' health [6] and their exposure to toxic elements contained in the mineralized gangue [7]. This paper aims to provide statistical information on accidents in this sector, through an analysis of the circumstances and key factors in their occurrence, examining their implications in terms of observed injuries, sequelae and work stoppages, as well as the nature of the provided care.

The ultimate goal is to identify the key factors in developing a strategy for prevention and management of occupational safety issues in this activity.

\section{MATERIALS AND METHODS}

The results presented in this study are derived from an investigation that was conducted in November 2009 on the LUPOTO site in the Katanga Province. Our study population consisted of miners in the mining area of Lubumbashi, which is one of three mining areas of this Province [8].

Our sample ( $\mathrm{N}=180$ ) was established by systematic random sampling from a list of 394 miners, a list prepared on the basis of a purchases register of the mine operator, holder of the concession on which these miners work.

The inclusion criteria in building this sample are:

- worked at least 12 months as a miner on this site,

- possessed an artisanal miner's card issued by the relevant administrative services,

- agreed to participate in the survey.
In this survey, we used a questionnaire validated by public health experts, which included three major parts: 14 questions on socio-demographic and behavioral characteristics, 14 questions related to the work and 26 other questions referring to accidents. It was translated into Swahili and administered by a team of 12 investigators. A pre-test was performed on 4 and 9 November 2009 and the survey effectively took place from 11 to 20 November 2009.

The results of the survey were encoded using MS Excel 2007 and the analysis was performed using SPSS version 17 and Epi Info. We used conventional statistics to describe the various aggregates obtained and the Pearson chi-square to verify the existence of an association between the variables studied. When the conditions of the application of Pearson chi-square were not met, we used Fisher's exact test.

To be able to interpret in a suitable way the results of this survey, we dichotomized some variables to split our sample into two comparable groups. As in the previous studies [9], we selected the threshold of 25 years for the age variable and, for seniority, the threshold of three years which represents the time after which many artisanal miners choose to remain or to leave this activity. As regards alcohol, we used the threshold of three bottles of beer per day (bottles of $72 \mathrm{Cl}$ ), which is the average quantity of consumption in the general population [10]. Local beers are graded at a rate of $6 \%$ of alcohol, and we used this rate to aggregate into a single variable the consumption of beer, liquors (knockoffs of certain industrial products) as well as indigenous alcohol (produced by fermentation of corn). To reflect the effects of the consumption of alcohol during working hours, we also interviewed the miners to determine whether they felt that they were under the influence of alcohol during their work. Similarly, given the importance of consumption of benzodiazepines and anti-inflammatory medicines in this population, we also attempted to assess the consequences of this self-medication as regards the occurrence of accidents, through a variable "effect of drugs". 


\section{RESULTS}

\section{Socio-demographic and behavioral description of artisanal miners}

The socio-demographic analysis of our sample (Table 1) shows that artisanal mining is primarily performed by male workers. The median age is 25 years and reading the 5th and 95 th percentile shows that $90 \%$ of the population falls within the range from 19 to 37 years. It is therefore a very young population and quite homogenous as for age. In total, $73.3 \%$ of these miners live with their families, which is an African tradition. Miners who live alone reside far from their home village, in makeshift camps erected around the mining sites.

Table 1. Socio-demographic and behavioral variables

\begin{tabular}{lc}
\hline \multicolumn{1}{c}{ Variables } & $\begin{array}{c}\text { Respondents } \\
(\mathrm{N}=180) \\
(\%)\end{array}$ \\
\hline Age (years) & \\
$\leq 25$ & 52.8 \\
$>25$ & 47.2 \\
Sex & \\
$\quad$ male & 86.7 \\
female & 13.3 \\
Life status & \\
living alone & 26.7 \\
living with family & 73.3 \\
Alcohol consumption & \\
great consumers & 52.8 \\
low consumers & 16.6 \\
no alcohol & 30.6 \\
Tobacco & \\
yes & \\
Apprenticeship & 54.4 \\
yes & 32.8 \\
Night shift & \\
yes & \\
Seniority (years) & \\
$\quad 33$ & \\
$>3$ & 29.4 \\
\hline
\end{tabular}

It is also apparent from Table 1 above that alcohol consumption is relatively high in this population (69.4\%). Based on the average amount of consumption in the general population, it appears that $52.8 \%$ of the miners in our sample should even be considered as heavy drinkers. Smoking is also relatively high in this population. Slightly more than a half of our subjects (54.4\%) smoke, with an average of 13 cigarettes per day and a standard deviation of 5 cigarettes.

From a professional perspective, Table 1 shows that $32.8 \%$ of these artisans reported having attended an apprenticeship to prepare themselves for their jobs. In addition, $29.4 \%$ of them work on night shifts. These are usually miners whose operating sites encroach on protected areas or have been closed due to accidents. In terms of experience, $83.3 \%$ totaled more than three years in this type of work.

\section{Analysis of variables related to accidents \\ Injury Incidence}

Over the 12 months preceding the study, $72.2 \%$ of the population of artisans in our survey (130 out of 180 subjects) experienced at least one accident. Table 2 below shows that $60 \%$ had at least two accidents during this period.

\section{Circumstances of occurrence and determinants of accidents}

We grouped into four categories the circumstances of occurrence of the 392 accidents reported in our sample. The frequencies of occurrence of each of these circumstances are presented in Table 3 below.

It is apparent from this table that accidents related to tools handling make the most numerous group. This is followed by handling heavy loads and falls. However, asphyxia during labor in underground tunnels is not very significant as for the number of cases.

In relation to the determinant factors of the accidents listed in Table 4 below, the observed frequencies within 
Table 2. Incidence of occupational accidents

\begin{tabular}{lccc}
\hline & $\begin{array}{c}\text { Accidents } \\
(\mathrm{n})\end{array}$ & $\mathrm{n}$ & Respondents $(\mathrm{N}=180)$ \\
\cline { 2 - 4 } & & 50 & 27.8 \\
\hline 0 & 22 & 12.2 \\
1 & & 108 & 60.0 \\
\hline 2 & &
\end{tabular}

Table 3. Circumstances of occupational accidents

\begin{tabular}{lcc}
\hline \multirow{2}{*}{\multicolumn{1}{c}{ Variables }} & \multicolumn{2}{c}{$\begin{array}{c}\text { Accidents } \\
(\mathrm{N}=392)\end{array}$} \\
\cline { 2 - 3 } & $\mathrm{n}$ & $\%$ \\
\hline Tools handling* & 202 & 51.5 \\
Handling heavy loads** & 129 & 32.9 \\
Falls & 45 & 11.5 \\
Asphyxia in underground tunnels & 16 & 4.1 \\
\hline
\end{tabular}

* Handling of shovels, pin bars, crushing hammers.

** Handling of bags of ore, sieves of gravel, transportation of bags.

the different clusters resulting from the dichotomization of our sample, show that such factors as age, seniority, or apprenticeship generate significant differences in terms of the occurrence of accidents. Regarding alcohol, however, a difference appears when the variable "work under the influence of alcohol" is taken into account.

\section{Lesions}

The 130 miners who reported having experienced at least one accident during the last 12 months also reported a total of 430 lesions which are stipulated in Table 5 below, grouped depending on the type of injury and their localization. It should be noted that there were no cases of burns among the reported accidents and that two miners reported accidents without an injury.

It is apparent from this table that the most common injuries include bruises and, like all other lesions, they affect the upper limbs. It is also worth noting that there was
Table. 4. Determinants of accidents concerning the examined subjects

\begin{tabular}{|c|c|c|}
\hline Variables & $\begin{array}{c}\text { Subjects who } \\
\text { experienced } \\
\text { accidents } \\
(\mathrm{N}=180) \\
(\%)\end{array}$ & $\mathrm{p}$ \\
\hline \multicolumn{3}{|l|}{ Age (years old) } \\
\hline$\leq 25$ & 38.9 & 0.643 \\
\hline$>25$ & 33.4 & \\
\hline \multicolumn{3}{|l|}{ Seniority (years) } \\
\hline$\leq 3$ & 9.9 & 0.102 \\
\hline$>3$ & 62.3 & \\
\hline \multicolumn{3}{|l|}{ Apprenticeship } \\
\hline yes & 26.1 & 0.120 \\
\hline no & 46.1 & \\
\hline \multicolumn{3}{|l|}{ Night shift } \\
\hline yes & 21.6 & 0.919 \\
\hline no & 51.1 & \\
\hline \multicolumn{3}{|c|}{ Working under influence of alcohol } \\
\hline yes & 23.3 & $<0.001$ \\
\hline no & 48.9 & \\
\hline \multicolumn{3}{|c|}{ Working under influence of drugs } \\
\hline yes & 12.8 & $<0.001$ \\
\hline no & - & \\
\hline \multicolumn{3}{|l|}{ Lack of training } \\
\hline yes & 36.1 & $<0.001$ \\
\hline no & - & \\
\hline
\end{tabular}

a surprisingly low number of fractures, which represent only $5.3 \%$ of all reported injuries, despite the relatively high frequency of landslides.

Presentation of the consequences of accidents In terms of the nature of care, Table 6 below shows that $80.5 \%$ of the miners who reported an injury received care from their colleagues or family members, without any recourse to medical staff. It should be noted that two miners reported accidents without injuries, thus reducing the 
Table 5. Types and localization of lesions

\begin{tabular}{lrrcr}
\hline \multirow{2}{*}{ Localization } & \multicolumn{4}{c}{ Lesions $(\mathrm{N}=430)$} \\
\cline { 2 - 5 } & bruises & wounds & fractures & total \\
\hline Head & 7.7 & 5.1 & - & 12.8 \\
Upper limbs & 25.3 & 21.6 & 3.5 & 50.5 \\
Lower limbs & 14.2 & 13.3 & 1.9 & 29.3 \\
Others & 3.0 & 4.4 & - & 7.4 \\
Total & 50.2 & 44.4 & 5.4 & 100.0 \\
\hline
\end{tabular}

total of casualties whose medical treatment can be analyzed to 128 individuals.

Based on these different modes of care, it also appears that $50.0 \%$ of sick leaves of three days or more, when care is provided by miners, were longer (even in relative values) than the $0.8 \%$ of sick leaves observed among miners who were cared for by the Red Cross Medical Units.
The analysis of sick leaves according to the types of lesions (Table 7) shows, in relative values, that more than twice the number of individuals who had wounds had work stoppages lasting for three days or more (4.7\% against 1.6\%), whereas nearly all of those who experienced only contusions did not stop working. On the other hand, all miners who experienced fractures stopped working for a prolonged period, which is normal given the time of fracture healing.

In 25 cases, the lesions resulted in physical sequelae. Compared to the total number of 128 accidents with consequential injuries, these sequelae represent over $19 \%$. Although the lesions themselves do not necessarily result in the change of a work site for the people who experienced accidents people, it appears that their sequelae forced $44 \%$ of the miners to change a work site after the experienced accidents.

Table 6. Importance of work stoppages based on the type of medical care provided

\begin{tabular}{lcccc}
\hline \multirow{2}{*}{ Kind of care } & \multicolumn{3}{c}{$\begin{array}{c}\text { Duration of work stoppage }(\mathrm{N}=128) \\
(\%)\end{array}$} & Total \\
\cline { 2 - 4 } & no stoppage & $\begin{array}{c}\text { stoppage } \\
<3 \text { days }\end{array}$ & $\begin{array}{c}\text { stoppage } \\
\geq 3 \text { days }\end{array}$ & 80.5 \\
\hline Care by miners and colleagues & 27.3 & 3.1 & 50.0 & 19.5 \\
Care by Red Cross facilities & 10.9 & 7.8 & 0.8 & 100.0 \\
Total & 38.3 & 10.9 & 50.8 & \\
\hline
\end{tabular}

Table 7. Work stoppages based on the types of lesions

\begin{tabular}{lcccc}
\hline & \multicolumn{3}{c}{$\begin{array}{c}\text { Duration of work stoppage }(\mathrm{N}=128) \\
(\%)\end{array}$} & \multirow{2}{*}{ Total } \\
\cline { 2 - 4 } Kind of lesion & no stoppage & $\begin{array}{c}\text { stoppage } \\
<3 \text { days }\end{array}$ & $\begin{array}{c}\text { stoppage } \\
\geq 3 \text { days }\end{array}$ \\
\hline Bruises only & 14.1 & 0.0 & 0.8 & 14.8 \\
Wounds only & 1.6 & 0.0 & 4.7 & 6.3 \\
Bruises and wounds & 22.7 & 10.9 & 28.9 & 62.5 \\
Fractures & 0.0 & 0.0 & 16.4 & 16.4 \\
Total & 38.3 & 10.9 & 50.8 & 100.0 \\
\hline
\end{tabular}




\section{DISCUSSION}

\section{On the importance of accidents and accident types}

The frequency of accidents in the population studied (72.2\%) is very high. This high level of accidents is reinforced by the observation that $60.0 \%$ of the injured miners actually experienced at least two accidents during the period included in the study.

In relation to the types of the observed accidents, it is interesting to note that 51 reported cases involved miners who did not have any break during their work day $(38.3 \%)$. These cases could be, if any, identified as incidents or "near misses", according to the classification proposed in the pyramid of Bird [11]. However, contrary to the conclusion derived from this pyramid, that the number of "incidents" is always proportionately higher than the number of accidents, in this case, it appears that these incidents were less frequent. This is explained by the nonperception of the concept of incidents by artisanal miners who, rightly, associate an accident with the damage, a concept absent in the incident.

This high level of accidents is actually not very far from that reported by the International Labor Organization, in a survey concerning social problems in small-scale mining, where fatal accidents were estimated at $2.5 \%$ of the miners involved [12]. However, this study notes that, given the clandestine nature of this activity, few accidents are really reported. The lack of reliable statistics also justified the use of a questionnaire.

Panda et al. [13], in a study of accidents in the textile sector in the DRC reported, using a questionnaire, a prevalence of $60.5 \%$ of accidents, a level that is close to that presented here.

The analysis of circumstances of occurrence of these accidents tends to confirm the negative influence of operational tools and techniques. Indeed, for $84.4 \%$ of miners, the accidents are caused by a problem of handling tools or heavy loads. This observation matches that described by Kecojevic et al. [14], who, in a retrospective study on the causes of accidents in mines in the United States, also noted that in the area of industrial mining, equipmentrelated accidents accounted for between $37 \%$ and $88 \%$ of the cases reported during a year.

The above report of ILO proposes a division of the causes of accidents in this sector into two broad categories: those related to the management and operations and those related to equipment and workplaces. Among the cases most often mentioned, this study incorporates: scree and slumps, slips and falls, old or poorly maintained equipment, etc.

So far, studies on health issues in artisanal mines have been more oriented towards environmental risks [15] (use of mercury) and few statistics are available as for accidents. However, since the causes and circumstances of these activities are quite common [16], this would suggest that the level of accidents and the conditions of occurrence that we saw should not be fundamentally different from those which emerge from the artisanal mining in other countries [17].

\section{On the influence of socio-demographic, behavioral and professional factors}

The analysis of the level of accidents according to age groups showed no significant difference in contrast to other studies reporting higher frequencies of accidents in the younger age groups. Such is the case of Laflamme et al. [18], who, in a survey conducted in Swedish iron mines, obtained a low accident rate among older miners. They justified this difference by unequal exposure to risk arising from the fact that the distribution of tasks incorporates the concept of aging of individuals and reserves more consuming tasks to younger workers.

In our case, the lack of difference between older and younger miners can be explained by the fact that $90 \%$ of our study population is in the 19-37 age group. The tightening of the population around the median may result in a relative neutrality of this factor. This finding would be 
enhanced by low differentiation of tasks performed by different team members, depending on their age.

It should be noted that other authors did not observe statistically significant differences in terms of the occurrence of accidents according to age, particularly in the mining sector [19]. In a review of the literature on the association between age and workplace accidents, Salminem [20] brought a nuance to this observation by stating that younger miners have more non-severe accidents, while aged miners are more prone to serious accidents.

In our sample, the frequency of accidents according to the seniority did not present a significant difference. This finding also goes against the idea that seniority plays a protective role in the occurrence of accidents. Indeed, in an analysis of 212 reports on serious accidents in the mining sector in Spain between 1982 and 2006, Sanmiquel et al. [21] came to the conclusion that $42.5 \%$ of serious accidents in the mines involved workers with less than four years' experience.

However, there are other works that have not confirmed this protective effect of seniority. This is the case of the research by Kecojevic et al. [22] who found that in the industrial sector of mining where more complex technology is used, the difference between workers with more experience (5 years) and others was not statistically significant, whereas the majority of these accidents were related to the problem of equipment handling.

In the particular case of artisanal mining, the lack of protective effect of age could be justified with the rudimentary nature of the technology, which minimizes the contribution of experience in the safety of the workers. The simplicity of the technology would be crucial in a context where the majority of accidents are related to a problem of tools handling.

We were also intrigued to find that the use of alcohol was not in itself a determining factor in the occurrence of accidents, unlike the variable "work under the influence of alcohol". This should be the consequence of a certain irregularity in the use of alcohol, to the extent that in a survival activity, artisanal miners do not always have the resources to buy alcohol. It is for this reason that the miners who admit to having worked under the influence of alcohol, have the level of accidents statistically significant compared to the others. This explanation is similar to the findings of Kunar et al. [23], who, by comparing two groups of workers with a control population, found significant differences in the association between accidents and alcohol use, but only as regards night workers. They justified this result by the fact that night workers were in the habit of drinking before their work, while others drank after it.

The significant difference in the occurrence of accidents in relation to "work under the influence of drugs" is congruent with the finding from the previous investigation in this activity [24], which had not only shown the importance of self-medication, but also pointed out a regular use of antiinflammatory drugs and benzodiazepines to fight pain. In this study, $89 \%$ of the miners reported benzodiazepine use, either to treat sleep disorders $(90.9 \%)$ or to avoid getting tired. This finding on the consumption of benzodiazepines is also echoed by other studies on artisanal mining [25]. Similarly, we found the frequency of $33.7 \%$ of abnormal fatigue among the miners [26]. This state of fatigue, associated with the use of alcohol and benzodiazepines (mainly valium), might constitute an association of important determinants in the occurrence of accidents in artisanal mining in Katanga.

Finally, the importance of the lack of training also needs to be pointed out, considering that this activity takes place outside the law and disregards the rules of professional mining. However, it should also be noted that the observed inadequate training may increase the exposure of the miners. Indeed, because they think that they are properly trained, these miners usually work with zeal unrelated to the real control of risk factors suitable for the profession. A previous study in the Katanga mines [27] had shown that the miners who received training through apprenticeship 
provided by former miners, showed more symptoms of illness and higher frequencies of health problems related to mining activity than those who had not received such an initiation. This observation shows the negative impact of inadequate training in addressing the real issues of prevention of health problems and safety.

\section{On the importance of injuries, types of care and work stoppages}

The first observation derived from the analysis of injuries caused by accidents in artisanal mining and their consequences, is that these accidents include mainly bruises and lesions that are usually not disabling. Indeed, bruises which represent $50.2 \%$ of the reported injuries hardly caused a work stoppage when not associated with another lesion (wound or fracture). It is different for wounds and fractures. However, this finding is far from reflecting the actual severity of accidents in this sector since it is influenced by the effects of "Healthy Worker Effect". Indeed, the selection effect, related to the "Healthy Worker Effect" [28], influences the results of a survey in the workplace, given the fact that only healthy workers are present at the time of investigation and may be interviewed (and not, for example, the victims of permanent cessation of work). It is, therefore, conceivable that effectively disabling accidents were more numerous, which is also the case in fatal accidents. Unfortunately, the low level of medical care observed in this activity does not allow us to conduct a survey on occupational health on the basis of medical records of the facilities to which those involved in accidents might have been brought.

The relatively high number of miners who did not experience a work stoppage despite an accident (38.3\%) mainly reflects the fact that this business is a survival activity, providing everyday low incomes that are barely sufficient to stave off poverty [29]. The accident victims need to return to work as quickly as possible, even to the detriment of their health and their recovery, otherwise they would be unable to support themselves. On the other hand, the fact that the majority of these lesions affect mainly the upper limbs is, in our opinion, a further confirmation of the harmfulness of the tools used in this profession, as also recognized by the miners themselves.

The importance of self-care, even in the cases of open fractures, also seems to be a consequence of the precarious situation that characterizes this population. For this reason, one might fear that only the most severe cases and complications of lesions initially treated by the miners themselves are reported at medical facilities. The persons treated in medical facilities spend more time on a sick leave than those treated by self-care. The fact that this observation has not been verified helps to reinforce the need for real health care promotion in this environment. Indeed, almost all of the injured workers treated by the Red Cross Facilities experienced a work stoppage lasting shorter than three days against only half-a-day sick leave in self-care situations.

Regarding the physical effects of accidents, their relatively low level could possibly be a consequence of the "Healthy Worker Effect", although they remain statistically significant for wounds and fractures. This also explains why, despite their small numbers, the reported sequelae generally led to a change of workplace, paradoxically strengthening the evidence concerning the potentially very dangerous aspect of artisanal mining.

\section{CONCLUSION AND RECOMMENDATIONS}

Although risk is inherently high in mining and artisanal mining as an activity carried out for survival and conditions of insecurity can only exacerbate these dangers, it is, nevertheless, true that the high level of accidents observed in this population is unacceptable. This finding is particularly appropriate since it is obvious that the nature of the tool used for this survey did not allow for the identification of fatal or permanent disabling. 
Given the factors and circumstances of occurrence of these accidents, prevention strategies should take into account the improvement of equipment whose crudeness is associated with the majority of accidents. However, the frequency of accidents, even in the industrial sector, led to a moderation of the expected effect of mechanization or effective use of personal protective equipment in reducing the number of accidents. These measures are not in themselves a panacea for decreasing the number of accidents, yet they are not easily possible in the context of a survival activity. Instead, a serious effort in training that meets the requirements for professional mining standards and a change in consumption habits (effects of alcohol and drugs) could lead to better management of accidents in this environment.

A better integration of incidents and better awareness of artisans not only about accidents but also about incidents will help to focus prevention efforts on reducing the number of harmless events which are predictors of accidents. Indeed, it is generally less expensive to obtain significant results in reducing the number of accidents by addressing incidents and accidents themselves. However, the likelihood of a serious accident decreases proportionally to the reduction in the number of incidents.

As for injuries and other consequences of these accidents, organization of a better medical care seems to be an important factor. And, given the scarcity of resources for artisanal miners, better management of accidents in this sector will be largely dependent on the solutions of risk pooling, including through the accountability of all persons who benefit from this form of operation.

\section{REFERENCES}

1. Ural S, Demirkol S. Evaluation of occupational safety and health in surface mines. Saf Sci 2008;46:1016-24.

2. Pact Inc. PROMINES study: Artisanal Mining in Democratic Republic of Congo. Washington: Pact Inc; 2010. p. 1-165.
3. Elenge MM, De Brouwer C. Problems of pathologies related to toxicological risks in small scale mining. Case of Katanga Province (D.R.C.): A review of literature J Int Santé Trav 2010;1:28-39.

4. The World Bank. Democratic Republic of Congo growth with governance in the mining sector. Report nº3402-ZR. Washington: The World Bank; 2008. p. 1-149.

5. Elenge MM, De Brouwer C. Identification of hazards in the workplaces of artisanal mining in Katanga. Int J Occup Med Environ Health 2011;24(1):1-10.

6. Elenge MM, Aubry JC, De Brouwer C. Health impact of working conditions at the Ruashi mine in the Democratic Republic of Congo. Med Trop 2009;69:488-92.

7. Elenge MM, Aubry J, Jacob L, Brouwer CD. Quantification of metal in the hair of copper miners in Katanga Province, Democratic Republic of Congo. J Environ Anal Toxicol 2011;1(4)114. p. 1-6. DOI: 10.4172/2161-0525.1000114.

8. AGAB. Map of the cupperbelt of DRC [cited 2006 Mar 30]. Available from URL: http://www.agab.be/mineralogie/Katanga/cartes.html.

9. Elenge MM, Aubry JC, De Brouwer C. Health impact of working conditions at the Ruashi mine in the Democratic Republic of Congo. Med Trop 2009;69:488-92.

10. Mukenga A. Evolutive study of the size of the beer market in Katanga [cited Nov 2010]. Lubumbashi: University of Lubumbashi; 2010. Available from URL: http://www.memoireonline.com.

11. Zimmermann C. Training in the prevention of occupational risks in a complex system: the link between perception, prescription and representation for acting [cited Nov 2010]. SaintMartin-d'Hères: University of Pierre Mendès France; 2010. Available from URL: http://www.memoireonline.com.

12. International Labour Organisation. Social and labour issues in small-scale mines. Geneva: OIT; 1999. p. 1-105.

13. Panda JP, De Brouwer C. Study of factors associated with the occurrence of accidents in the textile industry in the Democratic Republic of Congo. Arch Mal Prof Environ 2010;71(2):171-9. 
14. Kecojevic V, Komljenovic D, Groves W, Radomsky M. An analysis of equipment-related fatal accidents in U.S. mining operations: 1995-2005. Saf Sci 2007;45(8):864-74.

15. Bose-O'Reilly S, Drasch G, Beinhoff C, Tesha A, Drasch K, Roider $\mathrm{G}$, et al. Health assessment of artisanal gold miners in Tanzania. Sci Total Environ 2010;408(4):796-805.

16. Hilson G. Small-scale mining, poverty and economic development in sub-Saharan Africa: An overview. Resour Policy 2009;34:1-5.

17. Grätz T. Moralities, risk and rules in West African artisanal gold mining communities: A case study of Northern Benin. Resour Policy 2009;34:12-7.

18. Laflamme L, Menckel E, Lundholm L. The age-related risk of occupational accidents: The case of Swedish iron-ore miners. Accid Anal Prev 1996;28(3):349-57.

19. Butani SJ. Realtive risk analysis of injuries in coal mining by age and experience at Present Company. J Occup Accid 1988;10:209-16.

20. Salminem S. Have young workers more injuries than older ones? An international literature review. J Saf Res 2004;35(5):513-21.

21. Sanmiquel L, Freijo M, Edo J, Rossell JM. Analysis of work related accidents in the Spanish mining sector from 1982-2006. J Saf Res 2010;41:1-7.
22. Kecojevic V, Komljenovic D, Groves W, Radomsky M. An analysis of equipment-related fatal accidents in U.S. mining operations: 1995-2005. Saf Sci 2007;45(8):864-74.

23. Kuunar BM, Bhattacherjee A, Chau N. Relationships of job hazards, lack of knowledge, alcohol use, health status and risk taking behavior to work injury of coal miners: A case-control study in India. J Occup Health 2008;50:236-44.

24. Elenge MM. Adequacy of the mining legislation to the constraints artisanal mining. Congo Afr 2008;425:373-80.

25. Keita S. Small Scale Mining in Mali. Min Miner Sust Dev 2001;80:1-54.

26. Elenge MM, Aubry JC, De Brouwer C. Health impact of working conditions at the Ruashi mine in the Democratic Republic of Congo. Med Trop 2009;69:488-92.

27. Elenge MM. Adequacy of the mining legislation to the constraints artisanal mining. Congo Afr 2008;425:373-80.

28. Checkoway H, Pearce N, Crawford-Brown DJ. Research methods in occupational epidemiology. Oxford - New York: Oxford University Press; 1989. p. 78-9.

29. Hilson GM. The socio-economic impacts of artisanal and small-scale mining in developing countries. J Clean Prod 2006;14:1184-5.

This work is available in Open Access model and licensed under a Creative Commons Attribution-NonCommercial 3.0 Poland License - http://creativecommons.org/ licenses/by-nc/3.0/pl/deed.en. 